\title{
The effectiveness of military service experience on job experience
}

\author{
Donghwan Lee ${ }^{*}$ Yunyoung Jung ${ }^{* *}$
}

This study aims to determine the effectiveness of the military service experience on the job experience. Although people have passionately focused on discussions on the transition of the conscription system, relatively few studies have been conducted on the relationship between the military service experience and the individual job experience. In addition, prior studies on the relationship between the military service experience and the job experience have produced inconsistent results, and have narrowly focused on quantitative labor market variables such as pay and employment status. To fill these research gaps, we conducted this study by simultaneously using the following quantitative and qualitative outcome variables: pay, employment status, job satisfaction, and perceived job-required capacities. In addition, we explained the study results using distinct halo and sigma effects from antecedent studies that used human capital theory and the screening effect for applying national differences between the USA and South Korea.

() (1) This work is licensed under a Creative Commons Attribution 4.0 International License.

* (First Author) Korea Military Academy, Department of Business, Instructor, hwan8739@gmail.com, orcid 0000-0002-5217-6804

** (Corresponding Author) Korea Military Academy, Department of Business, Assistant Professor, 4348901@gmail.com, orcid 0000-0001-7667-0746 
To compare the differences between the military-experienced and unexperienced groups, we conducted a chi-square test and an independent t-test. The results showed that the military service experience is positively related to pay and employment status as well as to some measures of job satisfaction and perceived job-required capacities.

Keywords : military service experience, job experience, screening effect, halo effect, stigma effect 


\section{I. 서론}

병역의 의무가 남성만의 의무에서 국민의 의무로 확장될 날이 머지않았는지도 모른다. 대한민국 은 국가 최고법인 헌법 제 39 조 1 항에 모든 국민이 법률이 정하는 바에 의해 국방의 의무를 진다고 명시하였으나, 하위법인 병역법 제 3조 1 항에 남자에게는 의무복무를, 여자에게는 지원자에 의한 복무를 명시하고 있다. 하지만, 저출산으로 인한 인구절벽 현상이 두드러지게 나타나며 징병 가능 인원이 감소하고, 군 복무 개월 수 역시 18 개월로 단축되자 병역제도의 변화가 필요하다는 주장이 제기되고 있으며, 이는 모병제의 도입과 여성 징병제에 대한 담론을 포함한다. 2020년 KBS가 자사 국민패널 1,012 명을 대상으로 한 조사에서는 응답자의 $61.5 \%$ 가 모병제 도입에 찬성한다는 응답을 보였으며, 반대한다는 응답은 $28.8 \%$ 에 그쳤다. 또한, 동일한 조사에서 여성 징병제 도입에 대한 질 문 역시 찬성이 $52.8 \%$ 반대는 $35.4 \%$ 로 찬성 인원이 과반을 넘은 것으로 보아 사회변화로 인한 병 역의 형평성 문제가 새롭게 강조되고 있음을 보였다.1) 인구절벽으로 인한 모병제 도입에 대한 논 의는 Lee \& Kang (2017)이 2000년 초부터 심화된 저출산 문제가 병역자원의 감소뿐 아닌, 생산가 능인구의 감소를 함께 야기하기 때문에 모병제의 도입을 경제적으로 검토해 볼 필요가 있다고 주 장한 이후 지속적으로 제시되어 왔다. 그러나 모병제 도입에 대한 찬성뿐 아니라 여성 징병제에 대 한 찬성이 과반을 넘었다는 것은 괄목할 만한 변화이며 그만큼 병역이 국익과 국민 생활에 미치는 영향이 크며, 국민이 병역제도의 변화에 관심을 기울이고 있다는 것을 의미한다.

병역제도에 대한 담론이 많이 이루어지고 있는 것과는 다르게 군 복무경험이 향후 직업 경험에 미치는 영향에 대해서는 놀라울 정도로 선행 연구가 부족하다. 다음 장의 선행연구에 대한 분석에 서 드러나듯이 대부분의 연구가 군 복무와 직업 경험의 양적인 측면인 취업, 임금의 상관관계에 대 해서 제한적인 부분이나마 다루고 있으나, 국민적 관심과 국민 생활에 미치는 영향력에 비하면 그 수와 범위가 상대적으로 부족한 현실이다. 또한, 직업 경험의 질적인 측면인 정규직, 비정규직의 고 용 형태의 문제, 직장에 대한 만족의 문제, 그리고 직장에서 수행하는 업무의 수준 등에 대한 연구 는 찾아보기 어렵다. 어쩌면 이러한 연구의 부족은 대한민국 국민들이 군 복무경험이 향후 직업경 험에 미치는 효과에 각자의 확고한 견해를 가지고 있어 실증연구의 대상으로도 고려하지 않았기 때문일지도 모른다. 왜냐하면, 대한민국이 약 국민의 절반이 병역을 경험하는 국가이며 또한 병역 을 직접 경험하지 않더라도 주변인의 경험에서 병역을 간접적으로나마 경험하고, 이를 통해 병역에 대한 견해를 가지기 때문이다. 군 복무에 대한 간접 경험을 통한 견해의 형성에 대한 연구로는 Jung, T., Yu, Y., \& Kwak, J.(2016)의 연구가 있다. Jung et al.(2016)는 한국인이 군에 대부분 부정 적인 인식을 가지며 이러한 인식의 형성 배경은 주로 가까운 주변인의 영향요인이 크다는 것, 그리 고 대중매체가 군의 문제점을 지적하는 경향성이 크다는 것에 있다고 밝혔다. 이렇게 직 - 간접적 인 경험으로 형성된 견해는 개인의 경험차로 인해 일관성을 가지기 어려운데, 이러한 견해의 차이 
는 비슷한 시기에 실시된 설문을 통한 조사 혹은 연구에서 각기 상이한 응답을 보이는 점에서 실증 적으로 드러난다.

먼저, 군 복무가 향후 직업경험에 긍정적인 영향을 미친다는 견해가 있다. 한국직업능력개발원에 서 2015년에 분석한 자료2)에 따르면, 한국고용패널데이터를 활용한 2007년부터 2012년간의 응답자 3,226 명을 대상으로 한 조사에서 군 복무경험이 앞으로 할 일에 도움이 된다고 응답한 사람은 $55.8 \%$ 로 과반을 넘는 인원이었으며, 이는 학력이 높을수록 긍정적인 답변을 보였다. 군 간부 출신 은 5점 만점에 3.58점, 사병 출신은 2.93점으로 계급 간 차이가 유의미하게 나타나지만, 의무복무에 의한 군 복무를 마친 사병에게서도 과반 이상이 긍정 응답을 보인 것은 주목할 만한 부분이다. 또 한, 병무청이 2015년 현역병 4,626명을 대상으로 조사하고 발표한 「군 복무 병사의 신체와 의식변 화에 대한 조사」에 따르면 현역복무 기준인 1 급부터 3 급의 신체 등위 중 입대 이후 해당 등위의 향상을 보인 용사는 $34.3 \%$ 였으며 이중 3 급에서 1 급으로 2 개 급수 향상한 인원은 $4 \%, 3$ 급에서 2 급, 2 급에서 3 급으로 1 개 급수 향상한 인원은 각각 $8.1 \%$ 와 $22.2 \%$ 에 달했다. 또한, 의식 변화에 있어서 도 각각 책임감(71.5\%), 도전정신(67.4\%), 가족애(81.3\%), 대인관계(62.7\%), 안보의식(73\%)의 인원 들이 긍정적인 변화가 있었다고 응답하였다.3) 이처럼 군 복무가 향후 직업 경험에 긍정적인 영향 을 준다는 견해는 “군대를 다녀와야 철이 든다.”는 속설처럼, 군 복무 경험이 인내심, 리더십, 책임 감, 도전정신, 대인관계 등을 함양하고 강인한 체력을 길러준다는 장점에 주목하는 견해이며, 실증 적인 연구 결과보다는 개인의 경험과 이를 설문을 통해 측정하는 방식으로 형성 된다.

하지만 군 복무의 효과에 대해 긍정적인 측면만 존재하는 것은 아니다. 분명 군 복무가 경력단절 을 야기하여 향후 직업 경험에 제약사항이 될 것이라는 우려와 걱정이 존재하며, 또한 군 조직에 대한 불신이 공존하는 것이 사실이다. 군 조직에 대한 불신은 앞서 소개하였던 Jung et al.(2016)의 연구가 밝혔던 바와 같이 주변 사람에게 군에 대한 부정적인 견해를 확산시킴으로써 군 복무가 향 후 직업 경험에 부정적인 영향을 미칠 것이라는 견해로 이어진다. 현실적으로 군 복무 도중에 향후 취업을 준비하기에는 절대적인 시간이 부족한 것이 사실이기 때문에 군 복무가 직업경험에 부정적 인 효과를 가질 것이라는 견해는 반대 견해보다는 객관적인 근거를 지니고 있다고도 볼 수 있다. 이는 지금은 폐지되었으나 군 가산점 제도처럼 경력단절을 보상하기 위한 제도적 노력으로 나타나 기도 한다. 예를 들면, 정부는 군 복무로 인한 경력단절을 예방하기 위해 군 입대 전에는 근속 장려 금 제도, 복무 중에는 맞춤 특기병제, 제대 후에는 전역자에게는 취업성공수당, 그리고 고용기업에 게는 2 년간 법인세 $10 \%$ 세액공제 혜택을 주는 제도를 실시하고 있다. 실제로 2014년 해당 제도를 발표할 당시 경제부총리는 군 입대가 경력과 관련한 제약 요건이 되기 때문에 해당 제도를 그 대책 으로 한다고 명시한 바 있다.4) 또한, 군 조직에 대한 부정적인 인식으로 인해 군 복무가 개인의 능

2) 직업능력개발원(2015.06.30.), https://www.krivet.re.kr/repository/handle/201303/14788

3) 병무청 대변인실(2014.12.31.)

4) 청와대 정책브리핑 자료(2014.04.15.), http://www.ktv.go.kr/content/view?content_id=481335 
력 개발에 긍정적인 영향을 주지 못한다는 견해가 있는데, 이는 대군 인식조사와 연구에서 간접적 으로 드러난다. 먼저, $\operatorname{Kim}(2001)$ 은 입대 전 남성들을 대상으로 한 연구에서 군이 국가에 대한 경제 적 측면과 개인의 권익보호에 대한 필요성은 중요하게 인식되나, 군이 권위적, 비합리적, 불공평하 다는 부정적인 인식이 있다는 것을 밝혔다. 또한, 국방대학교에서 현대리서치 연구소에 의뢰하여 성인 남녀 1,200명과 전문가 60명을 대상으로 실시한 r2018 범국민 안보의식 조사 및 정책 대안 연 구」에 따르면, 응답자의 $46.7 \%$ 는 군을 신뢰한다고 밝혔고, $46.8 \%$ 는 군을 신뢰하지 않는다고 응답 했다. 여기서 신뢰하지 않는다는 응답의 이유로 군의 불합리한 관행 및 부조리가 $59 \%$, 빈번한 사건 및 사고의 발생이 $46.9 \%$, 간부들의 도덕성 결여가 $43.9 \%$ 등으로 가장 높은 응답을 보였다.5) 이처럼 군 복무에 대한 견해가 경험으로 형성이 되고 있으며, 국민 생활에 미치는 영향이 크고, 국민의 주 요 관심사 중 하나인 군 복무의 효과에 대한 국민의 인식에 일관성이 부족하고 객관적으로 측정이 되지 않았다는 점에서 실증적인 연구가 요구되며, 이번 연구에서는 그 중에서도 특히 군 복무경험 이 향후 직업 경험에 미치는 영향에 대해서 분석하고자 하였다.

이번 연구에서는 군 복무경험이 이후 직업 경험에 미치는 영향을 살펴보기 위해 군 복무 경험자 와 면제자의 집단 간 차이를 분석하고자 한다. 왜냐하면, 연구의 표본을 군 복무 경험자와 미경험자 로 나뉘게 되면 여성이 미경험자에 포함되게 되면서 성별의 차이로 인한 차이를 발생시킬 수 있기 때문이다. 또한, 이번 연구는 군 복무경험과 향후 직업 경험의 양적, 질적인 측면에 대해서 다루고 자 하는데, 이에는 크게 두 가지 이유가 있다. 첫째는 군 복무경험과 양적인 종속변수에 관한 대부 분의 선행 연구들이 군 복무와 임금에 대해서 다루고 있지만 서로 상이한 결과를 보여주기 때문이 다. 해당 연구들의 결과들이 군 복무 경험과 임금이 정적 $(+)$ 상관을 보이나(Eom, 2009; Kim \& $\mathrm{Kim}, 2017)$ 상관관계가 없거나(Kim \& Choi, 2011) 상이한 결과가 나타났다. 이는 군 복무경험과 임금의 관계가 아직 완전히 밝혀지지 않았음을 시사한다. 그리고 둘째는 해당 연구들이 군 복무경 험이 직업 경험의 질적인 측면에 미치는 영향을 설명하지 않았기 때문이다. 왜냐하면, 해당 연구들 은 임금이나 취업 시기, 정규직 여부 등 계량화된 양적 조건만을 고려하였기 때문에 개인이 느끼는 만족감이나, 직장 생활에서 담당하는 업무의 질적인 수준 등에 대한 내용을 다루지 않았기 때문이 다. 이는 마치 테일러의 과학적 관리가 구성원의 동기가 경제적 조건에만 반응한다고 가정하고 심 리적 조건을 간과했던 것과 같이 지나치게 세상의 단편적인 부분만을 보여주고 있다. 2019년 문화 체육관광부에서 발간한 $\Gamma$ 한국인의 의식 및 가치관 조사 결과 보고서,에서 직업 선택의 중요 요소 상위 3 가지는 첫째는 수입으로 $38.8 \%$ 두 번째는 직업 안정성으로 $25.6 \%$, 마지막은 적성 및 흥미로 $16.1 \%$ 였다. 즉, 계량화할 수 있는 요소인 수입과 정규직 여부가 큰 비중을 차지하고 있으나, 적성 및 흥미 등 심리적인 요소도 간과할 수 없다는 것이다.6) 이번 연구에서는 직업 경험에 대해서 측정 할 수 있는 변수로 양적 변수로는 임금을 고려하였으며, 질적 변수로는 정규직 여부, 직장 만족과

5) 조선일보(2019.10.07.) https://news.naver.com/main/read.nhn?oid=023\&aid=0003478377

6) 문화체육관광부 여론과 정책브리핑(2019.12.18.) 
노동자가 느끼는 업무의 수준을 고려하였다. 이때 업무의 요구수준은 양적으로 일이 많은 것이 아 닌, 현재 하고 있는 업무가 어느 정도 수준의 능력을 요구하는지를 종합한 결과로 자기개발이 가능 하고 개인의 능력을 발휘할 수 있는 직장인지 아닌지를 해당 노동자가 어떻게 인지하고 있는지를 다룬 척도이다.

이번 연구에서도 대부분의 선행연구들과 같이 군 복무경험이 향후 직업 경험에 정적인 효과를 줄 것이라 예상하며 이는 군 복무 경험자와 면제자의 집단 간 차이로 나타날 것이라고 보았으나, 이론적 근거는 상이하다. 대부분의 선행연구들은 Becker(1980)의 인적자본이론(Human Capital Theory)을 이론적 근거로 하였는데, 이는 개인이 축적한 인적자본의 수준과 취업 및 임금이라는 노동시장의 성과가 정적(+) 상관관계를 가진다는 이론이며, Angrist(1995)는 이를 군 복무 과정에 적용하여 군 복무 경험이 인적자본의 수준을 높이고, 이것이 고용률과 정적(+) 상관관계를 가진다 는 것을 밝혀냈다. De Tray(1982)는 군 복무 경험이 정신적, 육체적 능력을 향상시키기에 노동시장 에 빠르게 적응하고 이는 취업과 임금에 정적(+) 상관관계를 지닌다고 주장하였다. 국내 연구(Kim $\& \operatorname{Kim}(2017), \operatorname{Eom}(2009)$ 의 경우, 역시 군대가 인적자본을 축적시키고 임금, 취업, 구직기간 등에 정적(+) 영향을 미치는 것으로 나타났다.

하지만, 이번 연구에서는 인적자본이론(Human Capital Theory)을 이론적 근거로 하지 않는다. 왜냐하면, 모병제로 내적 동기에 의한 군 복무를 하고, 군 복무에 대한 인식이 긍정적인 미군의 경 우에는 다르게 한국군의 특성상 징병제에 의한 의무복무를 수행하며 군 복무를 하는 기간에 본인 의 전공과 연계된 특기와 보직에서 근무하는 인원이 드물고, 또한 군 복무 2 년이 사회에서 취업준 비를 하며 스펙을 쌓는 시간보다 인적자본을 많이 쌓아서 군필자의 고용효과가 높다고 주장하기에 는 제한사항이 있기 때문이다. 실제로 병무청이 2015년 현역병 4,626명을 대상으로 조사하고 발표 한 r군 복무 병사의 신체와 의식변화에 대한 조사」에서도 군 복무가 인생에 도움이 된다는 응답은 전체의 41.8\%인 1,932명에 그쳤다.7) 또한, 2019년 한국여성정책 연구원의 세미나(2019 변화하는 남 성성을 분석한다 - 성평등 정책의 확장을 위해)에서 전국 만 19세 59세 남성 3,000명에 대해 조사 한 설문 결과에 따르면 20대 남자의 경우 군 복무는 시간 낭비라고 응답한 비율은 $68.2 \%$ 이며 군 복무가 잃을 것이 더 많다는 응답은 $73.5 \%$ 였으나 군대를 다녀와야 사람이 된다고 응답한 비율은 $50 \%$ 에 그쳤다.8) 즉, 실제로 징병의 대상이자 군 복무를 가장 최근에 경험한 인원들의 생각에 군이 인적자원개발에 큰 도움이 된다고 생각하는 인원이 적다는 것이다. 이러한 설문조사의 결과를 바탕 으로 할 때 미국과 한국의 병역에 대한 인식이 상이하므로 미국에서 한 연구들의 논리를 한국사회 에 그대로 적용하는 것은 자칫 성급한 일반화의 오류를 범할 수 있다.

이번 연구에서는 한국의 군 복무 경험과 직업경험에 미치는 영향은 인적자본이론보다는 고용주 에 의한 선별효과(screening effect)가 군 복무 경험과 향후 직업 경험에 영향을 주었을 것이라고

7) 병무청 대변인실(2014.12.31.)

8) 한국여성정책연구원 개원 36주년 기념 세미나(2019.04.18.) 
보았다. 미국의 선별효과에 대한 대표적인 연구는 De Tray(1982)의 연구가 있다. De Tray(1982)는 고용자들이 피고용인의 생산성에 대한 직접적인 측정이 제한되기 때문에 비대칭적인 정보를 해소 하기 위해 선별 기제(Screening device)를 이용하게 되고, 군 복무 경험자들이 신체적, 정신적으로 군 복무를 경험하면서 각종 검사와 훈련을 통해 일정 수준 이상을 달성한 사람들이기 때문에 선별 기제로 작용하여 고용인들이 군 복무 경험자를 우선적으로 선발하게끔 한다는 것이다. Kim \& $\operatorname{Kim}(2017)$ 은 이를 신호이론(Signaling theory)을 통하여 설명하였는데, 능력이 있는 사람이 더 높 은 수준의 교육에 투자하는 기회비용이 적기 때문에 학위, 자격증 등의 선별 기제 역할을 할 수 있 는 지표들에 투자할 가능성이 높고, 이는 고등 교육을 받은 사람들이 실제로 능력이 있는 사람일 가능성을 높인다는 것이다. 이러한 메커니즘이 고용주에게는 신호(Signaling)가 되어 고용주가 고 등 교육을 받은 사람을 선발하게끔 한다는 것이다.

하지만 인적자본이론과 같이 신호이론과 선별효과 역시 한국에서 군 복무경험이 가지는 효과를 완전히 설명하기가 힘든데, 이는 모병제 국가인 미국과는 다르게 한국은 일반적으로 성인 남성이 군 복무 경험을 가지고 있기 때문이다. 즉, 모병제로 인하여 일부 선별된 인원만이 군 복무를 수행 하는 미국과는 달리 한국의 경우에는 징병제로 인하여 대다수의 한국 남성이 병역의 의무를 수행 하기 때문에 군 복무 경험이 특별하게 받아들여지지 않으며, 일반적인 성인 남성과 일부 모병제 여 성들의 경험으로 받아들여지기 때문이다. 이번 연구에서는 성인 남성이 군 복무를 정상적으로 수행 했는지, 혹은 그렇지 못하였는지에 대한 사회적인 인식이 고용주의 피고용인 채용 과정에 작용하기 때문에 고용에서 선별 효과가 이루어진다고 보며, 이를 심리적인 효과인 후광효과(Halo effect)와 낙인효과(Stigma effect)를 통해서 설명하고자 한다. 미국의 경우에는 군 복무를 자발적으로 수행 하고 군에 대한 신뢰가 높은 문화이기 때문에 군 복무경험이 후광효과(Halo effect)로 작용하여 고 용주들로 하여금 복무 경험자를 채용하고 싶도록 유인(Attraction)하기 때문에 미국의 선행연구와 같은 선별효과가 발생한다. 하지만 대한민국의 경우에는 대부분의 군 복무를 징병을 통해서 수행하 고, 엄격한 선발과정을 거치지 않기 때문에 미국과 같이 후광효과로 인한 선별효과가 발생한다고 보기에는 어렵다. 반면에 한국의 경우에는 군 생활을 정상적으로 수행하지 못하거나 혹은 마치지 못하였다는 사실은 고용주의 해당 인원에 대한 인식에 낙인효과(Stigma effect)로 작용하여 그를 채용 할 수 없도록 회피(Un-attraction) 시키는 것에 더 가까울 것이다. 이렇듯 군 복무 인원에 대 한 후광 및 낙인효과는 최근의 설문조사에서 미약하게나마 드러나는데, 2019년 한국여성정책원 세 미나(2019 변화하는 남성성을 분석한다 -성평등 정책의 확장을 위해-)에서 만 19세 59세 남성 3,000 명에 대해 조사한 설문의 결과가 이를 통계적으로 뒷받침 하였다. 설문 결과 군 복무에 대한 인식 조사에서 군대를 다녀와야 사람이 된다는 문항에 20 대는 $50 \%, 30$ 대는 $56.6 \%, 40$ 대는 $53.2 \%$, 50 대는 $67.6 \%$ 만큼 동의하였는데, 이는 군 복무 경험의 여부에 따라서 해당 사람에 대한 사회적 인식이 달라지고, 이는 고용주와 피고용인 관계에서는 낙인효과로 작용할 수도 있다는 것을 시사하 기 때문이다. 


\section{ㅍ. 이론적 배경 및 선행연구}

\section{1 군 복무와 노동시장에 대한 선행연구}

군 복무와 노동시장의 성과에 대한 미국에서의 연구는 최초에는 군 복무가 일종의 선별의 수단 으로 작용함으로써 군 복무 경험자에 대한 고용에 긍정적인 영향을 준다는 선별수단(Screening effect)의 역할을 한다는 것을 밝히고자 하였다. Little \& Fredland(1979)는 처음으로 군 복무 경험 자가 인적자원 개발을 통한 생산성 향상과, 고용주에 의한 선별 시그널로 인해 군 복무 경험과 임 금의 정적(+) 상관을 밝혀내었다. 그들의 연구결과는 인종과는 상관없이 군 복무 경험이 임금에 상 승효과가 있다는 것을 밝혀냈으나 이후 연구들에서는 사뭇 다른 결과를 보이기도 했다. De $\operatorname{Tray}(1982)$ 는 전쟁 시 군 복무 경험자들을 그들의 제대 후 군 복무 미경험자들과 비교하여 노동시 장에서 어떠한 성과를 보이는지에 대한 연구를 진행하였는데, 그는 군 복무경험과 임금의 정적 $(+)$ 상관관계를 인적자본 투자의 결과라기보다는 군 복무경험이 고용주에게 선별수단으로 작용했기 때문이라고 주장하였다. 이후 전후 군 복무 경험자와 미경험자를 비교한 연구들이 주로 진행되었는 데, Sampson and Laub(1996)은 세계 2차 대전 시 군 복무 경험자와 미경험자를 비교하였으며 해당 연구에서는 군 복무 경험자가 노동시장에서 군 복무 미경험자에 비해 높은 임금을 받는 것을 보였 다. 하지만, 같은 비교방법을 베트남 전쟁에 적용한 연구들, 혹은 한국 전쟁과 베트남 전쟁 참전 용 사들을 비교한 연구들(Berger \& Hirsch, 1983; Schwartz, 1986; Card 1983; Teachman, 2004)의 경 우에서는 유의미한 결과를 보이지 않거나, 심지어는 낮은 성과를 보이는 경우도 있었다. 즉, 전쟁 시 복무경험과 임금의 상관관계에 대한 연구들이 일관적인 결과를 보여주지는 않았다는 것이다. 또 한, 군 복무와 노동시장의 성과 차이가 인종에 따라서 달라짐을 분석한 연구들이 있었다. 먼저, Fredland \& Little(1985)와 Hisnanick(2003) 는 소수인종의 경우 군 복무 경험이 좋은 직업 진출을 위한 가교(Bridge) 역할을 해서 소수인종에 대한 차별을 극복할 수 있게 한다는 연구 결과를 보였 다. Teachman \& Call(1996)은 미군에서 백인의 경우 군 복무 경험자가 군 복무 미경험자에 비해 소득과 교육성취가 낮음을 발견하였고, Angrist(1998)는 흑인의 경우 군 복무 경험자는 미경험자에 비해 시간에 따른 소득의 상승폭이 미미하지만 장기간에 걸쳐 나타나지만, 백인의 경우에는 군 복 무 경험자가 미경험자에 비해 오히려 소득이 감소하는 것을 보였다. 인종차이에 대한 담론이 아닌 경력 단절과 군 복무의 인적자원 개발 효과를 연구한 비교적 최근 연구들도 존재하였는데, Richard \& Wilhite(1990), Teachman \& Tedrow(2007)은 군 복무가 오히려 경력단절 효과를 발생시켜 임금 감소효과를 발생시키기 때문에 군 복무 기간은 임금 감소효과를 가져오나, 군 복무 시 훈련 기간은 인적자본을 개발하여 임금의 상승효과를 가져온다는 것을 발견하였으며, Bauer \& Bender(2004)의 연구에서는 군 복무 경험자가 군 복무 미경험자에 비해 임금이 약 $3 \%$ 정도 높은 것을 발견했다.

하지만, 한국과 미국의 경우 문화와 군에 대한 인식도 상이하며, 연구의 시기에도 차이가 있다. 
The effectiveness of military service experience on job experience / Donghwan Lee $\cdot$ Yunyoung Jung 99

심지어는 병역제도마저 모병제와 징병제로 차이를 보이기 때문에 국내 연구자들은 대부분의 미국 선행연구에서 이론적 근거로 제시한 $\operatorname{Becker}(1980)$ 의 인적자본이론을 무분별하게 국내사례에 적용 하지는 않았다. Kim \& Choi(2011)의 경우에는 군 복무가 인적자원이론에 따라 군 복무 경험자를 개발하여 임금을 상승시킬 수 있으나, 군 복무가 사회와의 단절로 오히려 지식의 축적을 저해할 수 있으며 이는 인적자원형성을 제한하는 요소일 수도 있다는 중립적인 시각에서 연구를 진행하였다. 그들은 학력, 군 입대 시기, 군사 특기 등 여러 변수들을 복합적으로 고려하여 군 복무 경험이 취업 과 임금에 미치는 영향을 분석하고자 하였으며, 분석결과 군 복무경험이 취업과 임금 등 노동시장 성과와 유의미한 상관이 없다는 것을 밝혔다. $\mathrm{Eom}(2009)$ 은 군 복무가 인적자원을 개발한다는 담론 에 대해서는 다루지 않았으나 선행연구들의 방향성을 따라 군 복무가 인적자본 형성에 도움을 주 기 때문에 임금결정과 정적(+)인 상관관계를 가진다는 가설을 세우고, 이를 민서형(Mincerian) 임 금함수 추정을 통해 검증하였다. $\mathrm{Kim} \& \mathrm{Kim}(2017)$ 의 경우 군 복무 경험이 인적자원을 개발시킬 수 있다는 것과 더불어 고용주에게 선별기제(Screening device)로 작용하여 임금프리미엄을 제시 하기 때문에 군 복무의 임금효과가 있을 것이라고 주장하였으며, 분석결과 군 복무가 임금을 $7.1 \%$ 증가시킨다는 것을 발견하였다. $\operatorname{Kim}(2016)$ 의 경우에는 군 복무가 인적자본 형성에 도움을 준다는 논의에 공감하면서 복무유형을 세분화하여 현역복무자, 비대상자, 사회복무요원, 산업기능요원, 면 제자 등으로 나누어 분석하였으며 해당 복무유형이 구분되나 그 차이로 인해 취업 시기에 유의미 한 차이가 나지 않으며, 현역 복무자의 임금이 비대상자에 비해 유의미하게 높다는 것과 이러한 현 상이 전 소득분위에서 나타난다는 것을 확인하였다.

\section{2 후광효과(Halo effect)와 낙인효과(Stigma effect)}

후광효과(Halo effect)는 Wells(1907)에 의해 제시된 개념으로, 어떤 대상에 대한 일반적인 견해 가 그 대상이 가지고 있는 구체적인 평가에 영향을 준다는 것이다. 후광효과를 발생시키는 원인에 대해서 $\operatorname{Nam}(2016)$ 은 이를 크게 세 가지로 정리하였는데, 첫째는 부분이 가지고 있는 특성, 예를 들면 기업이 가지고 있는 이미지가 국가의 이미지를 결정하는 방식으로 나타날 수 있다는 것이다. 둘째는 개인이나 대상이 가지고 있는 현저한 특성이 그 사람의 덜 현저한 특성에 미치는 평가를 좌우한다는 것이며, 셋째는 후광효과가 사람이나 대상이 가지는 독립적인 특성들을 구분하지 못하 고 유사하게 평가하는 오류의 일종으로 보며, 이는 Newcomb(1931)의 오래된 견해와 일치한다. 심 리학적으로 개인이 가지고 있는 특성과 그의 행동에 대한 귀인에 미치는 영향력이 폭넓게 연구되 었고(Nisbett \& Wilson, 1977), 인상이 가지는 후광효과에 대해서도 연구가 되었으나(Anastasi, 1988), 이미지에 관련된 것이기 때문에 마케팅에서도 활발히 연구되었다. 예를 들면 $\mathrm{Kim} \&$ Lee(2008)는 이를 소비자가 상품에 가지고 있는 일부분의 현저한 특성을 통해서 전반적인 다른 특 성에 대해서도 평가를 하는 것이라 정의하였으며, 이를 $\operatorname{Park}(2004)$ 은 정보나 지식이 부족할 때 이 
러한 후광효과가 발생할 가능성이 높다고 하였다.

낙인효과(Stigma effect)는 심리학, 사회학, 경제학, 정치학 등 많은 학문에서 낙인이론(Labeling theory)의 범주에서 연구되는 효과이다. 미국의 사회학자이자 도시문제학 교수였던 Becker(1963)에 의하면 낙인효과는 처음 범죄를 저지른 사람에게 범죄자라는 낙인을 찍는 경우 의식적으로나 무의 식적으로 그렇게 행동하는 경우가 높아져 2차적으로 범죄를 저지를 가능성이 높아진다는 것이다. Major et. al. (1998)은 이러한 낙인찍기(Stigmatization)는 사회적인 맥락에서 가치가 낮다고 생각 되는 개인적인 속성을 가지고 있거나 혹은 사회적으로 가지고 있다고 여겨질 때 발생한다고 보며, Goffman(1963)은 낙인을 보편적인 사회현상이라고 보았으며, 외적인 기형(External deformities), 개인적인 성품, 혹은 정상에서 벗어났다고 판단되는 특징에 의해서 낙인이 발생한다고 보았다. 이 러한 낙인효과는 인종에 관해서 연구되거나(Twenge \& Crocker, 2002; Major et. al., 1998), 학업 성과에 대해서 연구되거나(Steele \& Aronson, 1995), 청소년, 상담학, 치료, 심리적 메커니즘 등 여 러 영역에서 연구되었다(Kim \& Seo, 2004; Shim, 2020; Han, 2020; Link \& Phelan, 2001).

이번 연구에서 군 복무 경험을 앞서 언급하였던 미국의 선행연구들이 제시한 선별기제 (Screening device)와 차이점을 지닌다고 본 것은 양국 간의 사회 - 문화적인 차이를 고려하였기 때 문이다. 미국에서 군 복무가 후광효과를 통한 선별기제로 작동할 수 있었던 배경에는 군 복무 간 얻은 지식과 경험이 차후 직장생활에 유의미한 능력을 개발하여 생산성을 높일 것이라는 인적자본 이론을 기반으로 한 사회적인 공감이 있었겠지만, 징병제를 통해 군 복무를 수행하는 사람들이 대 다수로 구성된 한국 사회에서는 당연한 의무를 수행하는 것으로 생각되어 후광효과로 적용된다고 보기에는 제한되기 때문이다. 물론, 서론에서 언급하였듯 여러 연구와 설문에서 아직 군 복무를 다 녀오는 것이 바람직하다는 사회적 인식이 드러나고 있으나, 당연한 의무로 지각되기 때문에 유의미 한 선별효과를 발생시킨다고 생각하기에는 어렵다는 것이다. 반대로, 낙인효과를 통한 선별효과는 두드러지게 나타날 수 있다. 군 복무를 경험하지 않은 남성에 대해서는 “아직 철이 들지 않았다." 라는 사회적으로 부정적인 인식을 공유하는 것 앞서 여성정책연구원의 설문에서 확인을 하였으며, 일반적으로 군 생활을 수행하는 것이 당연시되는 사회에서 군 복무를 수행하지 못하였다는 것이 일반적이지 못한 인적자원으로 부정적인 인식을 야기할 수 있기 때문이다. 이는 앞서 설명한 Goffman(1963)의 낙인효과에 대한 관점에서는 성인남성이 군 복무를 경험하지 않았다는 것이 정 상과 벗어나는 경우라는 선입견을 줄 수 있을 것이며, 이러한 부정적인 이미지가 고용주의 선발에 부정적인 영향을 줄 수 있기 때문이다. 
The effectiveness of military service experience on job experience / Donghwan Lee • Yunyoung Jung 101

\section{III. 연구방법}

\section{1 분석에 활용된 데이터}

이번 연구에서는 한국고용정보원에서 실시한 청년패널조사인 YP2007의 2018년 시행된 12번째 조사자료를 사용하였다. YP2007은 청년들이 학교에서 노동시장으로 이동하는 과정을 추적하기 위 해서 실시된 패널조사로, 2007 년을 기점으로 만 15 세부터 만 29세까지의 청년을 표본으로 시작되었 다. 2020년 기준으로 2018년 12번째 데이터까지 조사가 진행되었으며, 2007년 선정된 표본을 현재 까지 추적하여 수집 중이다. 이번 연구의 목적은 군 복무 경험자와 군 복무 미경험자의 직장의 질 을 측정하고자 하는 것으로, 2018년 기준 만 26세부터 만 40세까지의 표본을 대상으로 이루어지고 있는 연구이며 군 복무경험과 현재 고용상태에 대한 여러 정보들을 포함하고 있기 때문에 이번 연 구의 기초자료로 활용하였다.

이번 연구에서 사용한 12 차 데이터(2018년 측정)의 원표본은 10,206 명이다. 이중 이번 연구는 군 복무 경험자와 면제자를 비교하는 연구이기 때문에 군 복무 대상이 아닌 여성이거나, 군 복무 유형 에 응답하지 않은 인원을 일차적으로 6,802 명 제거하였다. 또한, 해당 인원 중 현재 취업을 하지 않 았거나, 고용형태에 대해서 미응답한 인원을 이차적으로 834명 제거하여 최종적으로 이번 연구에 활용된 표본은 2,575 명이다. 이 중 현역으로 군 복무를 경험한 인원은 2,367 명이며, 면제를 받은 인 원은 208 명이었다.

\section{2 분석방법}

이번 연구에서는 SPSS22 프로그램을 사용하여 분석을 진행하였다. 첫째로 정규직인지, 비정규 직 인지의 여부를 고용형태로 정의하여 군 복무경험자와 면제자의 실제 정규직, 비정규직의 기대빈 도와 빈도를 비교하였으며, 카이제곱 검정을 통해 군 복무자와 면제자의 정규직, 비정규직 여부의 차이가 통계적으로 유의미한지를 검정하였다. 이후 군 복무와 급여의 차이를 확인하기 위해 독립표 본 t검정을 실시하였으며, 군 복무 경험자와 면제자의 직무만족, 업무요구능력의 차이를 확인하기 위해 두 집단의 t-test를 실시하여 이를 비교하였다. 이때 직무만족, 업무요구능력, 자존감에 대한 측정 시에 이에 각 척도 중 집단에서 통계적으로 유의미한 차이를 내는 문항을 추출하여 이를 문항 별로 비교하였는데, 이는 각 설문 문항이 독립적으로 의미하고 있는 바가 있기 때문에 평균값이 아 닌 문항별로 차이가 나는 부분을 분석하고자 하기 위함이다. 마지막으로, 문항별 비교 결과 업무요 구능력에서 군 복무 경험집단이 면제집단에 비해 자존감과 관련이 있는 대인관계 능력을 필요로 하는 것을 확인하고, 자존감에 대해 군 복무 경험집단과 면제집단을 추가로 비교분석 하였다. 


\section{IV. 분석결과}

\section{1 군 복무여부에 따른 고용형태의 차이}

이번 연구의 첫 번째 가설은 고용형태와 군 복무 여부(2개 집단 : 복무, 면제)에 따른 고용형태의 차이점이 있다는 것이다. 표본크기는 2,575 명이며 결측치는 표본집단에서 차지하는 비율이 매우 낮 기 때문에 제거하였다. 설문조사 결과를 토대로 기술통계를 산출한 결과, 설문대상자 중 군 복무를 이행한 경우는 2,367명으로 대상자의 $91.9 \%$ 를 차지했고, 면제자는 208명으로 대상자의 $8.1 \%$ 였다. 두 집단의 인원비율 대비 정규직과 비정규직의 비율이 서로 차이가 있는지에 대한 검정을 실시(카 이제곱 검정) 하였다. 두 집단의 정규직 $\times$ 비정규직 교차표는 <표 $1>$ 과 같은 형태이고, 카이제곱 검정 <표 2>에서 동질성 분석을 실시하였는데, 그 결과, 카이제곱 값은 11.665 로, 유의확률은 0.001 로 유의수준 0.05 에서 군 복무자와 면제자의 정규직, 비정규직 비율이 같다는 영가설이 기각되므로, 군 복무 여부에 다른 정규직과 비정규직의 고용형태는 다르며, 기대빈도 대비 실제 정규직 빈도가 관측되는 비율이 군 복무 경험자에게서 높다는 점에서 실제로 면제자보다 군 복무 경험자의 정규 직 비율이 통계적으로 유의미하게 높다는 것을 알 수 있다. 즉 가설1은 채택되었다.

\section{2 군 복무 여부와 급여의 차이}

이번 연구의 두 번째 가설은 군 복무 여부와 급여(통상급여, 연)의 차이가 존재한다는 것이다. 이 를 확인하기 위해 두 집단의 독립표본 t-test를 실시하였으며, 대상자 중 결측치 123 개는 제거하였

<표 1> 고용형태 * 군 복무여부 교차표

\begin{tabular}{|c|c|c|c|c|c|}
\hline \multirow{2}{*}{\multicolumn{3}{|c|}{ 구 분 }} & \multicolumn{2}{|c|}{ 군 복무여부 } & \multirow{2}{*}{ 전체 } \\
\hline & & & 복무 & 면제 & \\
\hline \multirow{8}{*}{$\begin{array}{l}\text { 고용 } \\
\text { 형태 }\end{array}$} & \multirow{4}{*}{ 정규직 } & 빈도 & 2101 & 168 & 2269 \\
\hline & & 기대빈도 & 2085.7 & 183.3 & 2269.0 \\
\hline & & 전체 \% & $81.6 \%$ & $6.5 \%$ & $88.1 \%$ \\
\hline & & 표준화 잔차 & .3 & -1.1 & \\
\hline & \multirow{4}{*}{ 비정규직 } & 빈도 & 266 & 40 & 306 \\
\hline & & 기대빈도 & 281.3 & 24.7 & 306.0 \\
\hline & & 전체 \% & $10.3 \%$ & $1.6 \%$ & $11.9 \%$ \\
\hline & & 표준화 잔차 & -.9 & 3.1 & \\
\hline \multirow{3}{*}{\multicolumn{2}{|c|}{ 전체 }} & 빈도 & 2367 & 208 & 2575 \\
\hline & & 기대빈도 & 2367.0 & 208.0 & 2575.0 \\
\hline & & 전체 \% & $91.9 \%$ & $8.1 \%$ & $100.0 \%$ \\
\hline
\end{tabular}


The effectiveness of military service experience on job experience / Donghwan Lee • Yunyoung Jung 103

<표 2> 카이제곱 검정

\begin{tabular}{c|c|c|c|c|c}
\hline 구 분 & 값 & 자유도 & $\begin{array}{c}\text { 점근 유의확률 } \\
\text { (양측검정) }\end{array}$ & $\begin{array}{c}\text { 정확한 유의확률 } \\
\text { (양측검정) }\end{array}$ & $\begin{array}{c}\text { 정확한 유의확률 } \\
\text { (단측검정) }\end{array}$ \\
\hline \hline Pearson 카이제곱 & $11.665 \mathrm{a}$ & 1 & .001 & & \\
\hline 연속수정b & 10.914 & 1 & .001 & & \\
\hline 우도비 & 10.213 & 1 & .001 & & .001 \\
\hline Fisher 검정 & & & & \multicolumn{2}{c}{} \\
\hline
\end{tabular}

다. 기술통계량은 아래 <표 3>과 같으며 두 집단의 평균은 각각 3719 만 원, 3211 만 원이고, 표준편 차는 1,414 만 원, 1,231 만 원이다.

<표 3> 기술통계량

\begin{tabular}{c|c|c|c|c|c}
\hline 구 분 & 군 복무여부 & $\mathrm{N}$ & 평균 & 표준편차 & 평균의 표준오차 \\
\hline \hline \multirow{2}{*}{ 금 액 } & 1 & 2247 & 3719.44 & 1414.549 & 29.841 \\
\cline { 2 - 6 } & 2 & 200 & 3211.72 & 1231.933 & 87.111 \\
\hline
\end{tabular}

* 결측치 제거 : 123 개

먼저, 두 집단의 등분산성을 충족하는지 확인하기 위해 Levene의 등분산 검정방법으로 검정한 결과 $\mathrm{F}$ 통계값이 0.076 , 유의확률이 $\mathrm{P}=0.076$ 으로서, 유의수준 0.05 에서 두 집단의 분산이 같다는 가설을 기각할 수 있다. 즉, $\mathrm{t}$-test를 위한 등분산 가정을 충족하지 않으므로, 등분산이 가정되지 않 은 t-test 결과를 보아야 한다. t-test 결과, $\mathrm{t}$ 통계값은 5.514 으로서, 유의수준 0.01 에서 두 집단의 보수는 차이가 있음을 알 수 있다. 여기서 $\mathrm{t}$ - value는 평균차이를 차이의 표준오차로 나눈 값이다. 기술 통계량과 $\mathrm{t}$ - test 결과를 토대로 판단해 본 결과, 군 복무를 한 집단은 그렇지 않은 집단에 비해서 연간 보수 부분에서 유의미한 플러스(+) 효과가 있는 것으로 판단된다. 이 부분은 정규직과 비정규직의 차이에서 오는 임금의 차이, 호봉(군 생활 년 차에 따라 호봉 가산 적용) 인정에 따른 임금 차이 등의 요인이 있을 수 있으며, 양적인 측면에서 좋은 직장을 얻었다고 할 수 있다. 즉, 가 설 2 역시 채택되었다.

<표 4> 독립표본 검정

\begin{tabular}{c|c|c|c|c|c|c|c|c}
\hline \multirow{2}{*}{\multicolumn{2}{c|}{ 구 분 }} & \multicolumn{5}{|c|}{ Levene의 등분산 검정 } & \multicolumn{5}{|c}{ 평균의 동일성에 대한 $\mathrm{t}$-검정 } \\
\cline { 2 - 9 } \multicolumn{2}{c|}{} & $\mathrm{F}$ & 유의확률 & $\mathrm{t}$ & 자유도 & 유의확률(양쪽) & 평균차 & $\begin{array}{c}\text { 차이의 } \\
\text { 표준오차 }\end{array}$ \\
\hline \hline 금액 & 등분산이 가정 됨 & 3.148 & .076 & 4.913 & 2445 & .000 & 507.72 & 103.349 \\
\hline
\end{tabular}




\section{3 군 복무 여부와 직무만족도}

가설 3은 군 복무 여부와 직무만족도 사이에 유의미한 차이가 존재한다는 것이다. 직무만족도에 대한 설문조사는 15 개 항목으로 실시되었고, 각 질문은 만족부터 불만족까지 5 점 리커트 척도로 측 정되었다. 해당 내용에 대한 검증을 위해 문항별로 집단 간 비교를 t-test를 실시하였다. 직무만족 도에 대한 15 개의 질문들 중에 두 집단 간의 유의한 차이가 있는 질문은 6 번, 12 번 문항 외에는 없 었는데, 내용은 아래<표 $5>$ 와 같다. 일과 자율성과 권한, 여가생활 보장 등에서 두 집단 간의 유의 미한 차이점을 식별할 수 있었는데, 이는 정규직과 비정규직의 업무형태에 기인한 것으로도 생각해 볼 수 있다. 정규직의 경우, 비정규직에 비해서 복지여건(유급휴가, 복지금 - 카드 지급, 법정 근로 시간 준수 등)에서 차이가 나는데, 이는 여가생활을 보장하는 것과 큰 연관이 있다고 할 수 있는 부분이다. 또한, 정규직의 업무형태는 비정규직에 비하여 지시받는 업무의 영역보다 자율성과 권한 을 가지고 본인이 직접 기획 및 기안하는 업무의 영역이 더 크다고 볼 수 있는데 이는 업무의 자율 성과 권한보장과 직접적인 관련이 있는 부분이다. 즉, 일부 문항에서 집단 간 유의미한 차이를 보이 지만 정규직과 비정규직의 차이를 통제하지 않았기 때문에 부정확할 수 있는 결과이며, 대부분의 문항에서 유의미한 차이가 없다는 점에서 가설 3 은 기각되었다고 할 수 있다.

<표 5> 두 집단 간 유의미한 차이가 있는 설문항목

6. 일의 자율성과 권한

12. 여가생활 보장

<표 6> 직무만족도에 대한 독립표본 검정

\begin{tabular}{c|c|c|c|c|c}
\hline 질문 & 군 복무 여부 & Mean & $\mathrm{SE}$ & $\mathrm{t}$ & 유의확률(양쪽) \\
\hline \hline \multirow{2}{*}{6} & 군필 & 3.795 & .6039 & \multirow{2}{*}{-2.24} & .026 \\
\cline { 2 - 4 } & 미필 & 3.693 & .6855 & & \multirow{2}{*}{-2.13} \\
\hline \multirow{2}{*}{12} & 군필 & 3.605 & .6254 & .033 \\
\cline { 2 - 4 } & 미필 & 3.492 & .7247 & & \\
\hline
\end{tabular}

\section{4 군 복무 여부와 업무요구능력}

가설 4는 군 복무 여부와 업무요구능력 사이에 유의미한 차이가 존재한다는 것이며, 이를 검증하 기 위해 두 집단의 t-test를 실시하였다. 업무요구능력에 대한 설문 조사는 15 개 항목으로 실시되었 고, 각 질문은 만족부터 불만족까지 5점 리커트 척도로 작성되었다. 업무요구능력에 대한 설문 문 항에 대해 확인적 요인분석을 실시한 결과, 같은 요인으로 묶이는 문항이 존재하지 않았기 때문에 
The effectiveness of military service experience on job experience / Donghwan Lee • Yunyoung Jung 105

직무만족과 동일하게 업무요구능력의 평균값을 통한 비교가 아닌 문항별 집단 간 비교를 t-test를 통해 실시하였다. 업무요구능력에 대한 15 개의 질문들 중에 두 집단 간의 유의한 차이가 있는 질문 은 $1,2,3,8,9,11,14$ 번 질문 등 7 개 항목이었다. 아래 <표 $7>$ 에서 확인할 수 있듯이 군 복무를 이행한 집단과 그렇지 않은 집단이 차이를 보인 부분은 동료와의 의사소통(3번, 11 번), 실무적인 업 무능력(1번, 2번, 8번, 9번), 규칙적인 생활습관(14번) 등 실무 및 공동체 생활을 원활히 수행하기 위한 능력에 관련된 것들이다. 군 복무를 한 집단에서는 그렇지 않은 집단에 비해서 앞서 기술한 7개 항목에서 더 높은 점수를 보였는데, 이는 군 복무를 이행한 집단의 구성원들은 외국어 능력이 나 수학능력, 전문분야의 기술 습득 등 개인의 특별한 역량보다는 협력과 소통에 관련된 능력이 필 요한 직무에서 근무하는 경우가 많다는 것을 간접적으로 의미한다.

<표 7> 두 집단 간 유의미한 차이가 있는 설문항목

1. 문서나 글을 읽고 내용을 파악해서 처리하는 능력

2. 문서를 작성하거나 글을 쓰는 능력

3. 동료나 상사와 의사소통하는 능력

8. 컴퓨터를 사용하는 능력

9. 직무분야에 대한 지식

11. 타인과 협력하는 태도

14. 규칙적이고 계획적으로 생활하는 습관

<표 8> 업무요구능력에 대한 독립표본 검정 결과

\begin{tabular}{|c|c|c|c|c|c|}
\hline 질문 & 군 복무 여부 & Mean & $\mathrm{SE}$ & $\mathrm{t}$ & 유의확률(양쪽) \\
\hline \multirow{2}{*}{1} & 군필 & 3.768 & .9045 & \multirow{2}{*}{2.750} & \multirow{2}{*}{.006} \\
\hline & 미필 & 3.570 & .9848 & & \\
\hline \multirow{2}{*}{2} & 군필 & 3.737 & .9229 & \multirow{2}{*}{2.663} & \multirow{2}{*}{.008} \\
\hline & 미필 & 3.540 & 1.0116 & & \\
\hline \multirow{2}{*}{3} & 군필 & 4.091 & .7848 & \multirow{2}{*}{2.985} & \multirow{2}{*}{.003} \\
\hline & 미필 & 3.925 & .7497 & & \\
\hline \multirow{2}{*}{8} & 군필 & 3.819 & .9724 & \multirow{2}{*}{3.273} & \multirow{2}{*}{.001} \\
\hline & 미필 & 3.570 & 1.0394 & & \\
\hline \multirow{2}{*}{9} & 군필 & 4.098 & .8356 & \multirow{2}{*}{2.315} & \multirow{2}{*}{.021} \\
\hline & 미필 & 3.955 & .8465 & & \\
\hline \multirow{2}{*}{11} & 군필 & 4.0587 & .73467 & \multirow{2}{*}{2.992} & \multirow{2}{*}{.003} \\
\hline & 미필 & 3.8950 & .81689 & & \\
\hline \multirow{2}{*}{14} & 군필 & 3.9955 & .73881 & \multirow{2}{*}{2.022} & \multirow{2}{*}{.043} \\
\hline & 미필 & 3.8850 & .76466 & & \\
\hline
\end{tabular}




\section{5 군 복무 여부와 자존감}

추가적인 분석으로 군 복무 여부와 자존감의 차이를 확인하기 위해 두 집단의 t-test를 실시하였 다. 자존감에 대한 설문조사는 13 개 항목으로 실시되었고, 각 질문은 만족부터 불만족까지 5점 리 커트 척도로 작성되었다. 자존감을 측정하기 위한 13 개의 질문들 중에 두 집단 간의 유의한 차이가 있는 질문은 $2,5,6,7,8,9,13$ 번 질문 등 7 개 항목이었다. 유의미한 차이가 있는 설문 항목을 살펴 보면 두 집단이 문제해결 및 상황극복 능력(5번, 7 번, 8 번), 긍정적이고 자신감 있는 태도 등(2번, 6 번, 9번, 13번)에서 차이가 난다고 볼 수 있다. 즉, 군 복무를 한 집단은 그렇지 않은 집단에 비해서 문제 해결능력과, 대인관계에 대해서 긍정적으로 생각한다고 볼 수 있는데, 이는 업무요구능력에서 중요하게 생각하는 실무 및 공동체 활동을 하기 위한 요인과 유사하다. 군 생활에 대해 인적자본이 론을 부분적으로 적용한다면 자존감과 관련이 있으며, 이는 군 복무자들이 자존감 함양을 통해 직 장 경험에서 요구되는 능력을 갖출 수 있도록 유의미한 차이를 만들어 낼 수 있다는 것을 시사하 며, 자존감의 매개효과에 대해 후속 연구에서 살펴 볼 필요가 있다.

\section{$\mathrm{V}$. 결론 및 논의}

대한민국이 국민개병주의를 채택하고 병역제도를 징병제로 채택하고 있으며, 여성 징병제 및 모 병제로의 전환에 대한 여러 사회적 담론이 진행되고 있으나, 군 복무가 향후 직업 경험에 미치는 영향에 대한 연구가 부족하고 또한 최근 들어 이루어지지 않고 있다. 몇몇 연구자들이 선행연구에 서 군 복무경험이 향후 임금과 상관이 있다는 내용의 연구는 제법 진행되었으나, 연구의 결과 측면 에서 상이한 부분이 많으며, 임금과 취업상태와 같은 양적인 측면에서만 분석이 되었기 때문에 직 업경험의 질적인 측면에 대해서는 연구가 전무했다는 점에서도 아직 보완할 부분이 많다. 또한, 인 적자본이론과 선별효과에 다른 이론을 적용하는 방식에서 미국의 선행연구들과 동일한 논리로 한 국을 설명하기에는 정치·경제·사회·문화 - 제도적인 차이가 너무 크다는 점을 간과하고 있는

<표 9> 두 집단 간 유의미한 차이가 있는 설문항목

\begin{tabular}{l}
\hline 2. 가끔 인생의 실패자라고 생각한다. \\
\hline 5. 나는 나에게 어떠한 문제가 생겼을 때, 적절한 해결책을 찾을 수 있다. \\
\hline 6. 나는 남들에게 좋은 인상을 준다. \\
\hline 7. 나에게 업무가 주어지면, 그 일을 해결할 수 있는 효과적인 방법을 찾을 수 있다. \\
\hline 8. 나는 아무리 어려운 상황도 잘 극복할 수 있다. \\
\hline 9. 나는 매사에 자신감 있게 임한다. \\
\hline 13. 나는 여러 사람들 앞에서 이야기하는 것이 두렵지 않다. \\
\hline
\end{tabular}


The effectiveness of military service experience on job experience / Donghwan Lee • Yunyoung Jung 107

<표 10> 자존감에 대한 독립표본 검정

\begin{tabular}{|c|c|c|c|c|c|}
\hline 질문 & 군 복무 여부 & Mean & $\mathrm{SE}$ & $\mathrm{t}$ & 유의확률(양쪽) \\
\hline \multirow{2}{*}{2} & 군필 & 1.7364 & .87681 & \multirow{2}{*}{2.672} & \multirow{2}{*}{.008} \\
\hline & 미필 & 1.9100 & .91985 & & \\
\hline \multirow{2}{*}{5} & 군필 & 4.3335 & .83339 & \multirow{2}{*}{3.159} & \multirow{2}{*}{.002} \\
\hline & 미필 & 4.1400 & .78963 & & \\
\hline \multirow{2}{*}{6} & 군필 & 4.3669 & .82059 & \multirow{2}{*}{2.773} & \multirow{2}{*}{.006} \\
\hline & 미필 & 4.2000 & .75688 & & \\
\hline \multirow{2}{*}{7} & 군필 & 4.3366 & .80409 & \multirow{2}{*}{2.056} & \multirow{2}{*}{.040} \\
\hline & 미필 & 4.2150 & .76924 & & \\
\hline \multirow{2}{*}{8} & 군필 & 4.3130 & .80060 & \multirow{2}{*}{2.592} & \multirow{2}{*}{.010} \\
\hline & 미필 & 4.1600 & .79217 & & \\
\hline \multirow{2}{*}{9} & 군필 & 4.2801 & .84759 & \multirow{2}{*}{3.453} & \multirow{2}{*}{.001} \\
\hline & 미필 & 4.0650 & .80249 & & \\
\hline \multirow{2}{*}{13} & 군필 & 4.1999 & .88271 & \multirow{2}{*}{2.698} & \multirow{2}{*}{.007} \\
\hline & 미필 & 4.0250 & .82935 & & \\
\hline
\end{tabular}

부분들도 보완되어야 할 것이다. 군 복무가 향후 직업 경험에 미치는 영향은 보다 많은 부분에서 정밀하게 연구되어야 하는데, 이는 남성에게 편중된 병역의 의무에 대한 형평성과 보상의 문제를 보완할 근거가 되기 때문이다. 왜냐하면, 1999년 헌법재판소에 의해 군가산점제도가 폐지된 이후 군 복무에 대한 정부 정책 측면에서의 보상이 이루어지지 않고 있으며, 이로 인한 군 복무의 취업 제약 효과가 어느 정도인지 객관적으로 측정한 연구들이 없기 때문이다. 예를 들어 군 복무 경험자 가 면제자에 비해 고용시장에서 큰 불이익을 받고 있다면 정밀하게 불이익을 측정하고 해당 부분 을 보상하여 차이를 메꾸는 방법만이 형평성의 문제를 해결할 수 있을 것이다. 결론적으로, 군 복무 경험과 고용시장의 상관관계에 대한 연구는 징병제를 채택한 대한민국에서는 학문적, 실용적으로 필요하기도 하나, 당위성의 문제도 가진다는 것이다.

이러한 배경에서 이번 연구는 군 복무가 가지는 고용시장에서의 효과를 군 복무를 경험한 개인 의 특성으로 귀인한 것이 아닌, 후광효과와 낙인효과를 통한 선별효과에 귀인하여 새로운 시각으로 이를 고려하였으며, 미국과 한국의 국가적 차이를 구분하여 분석하였다는 점에서 이론적 의의를 지 닌다. 또한, 이번 연구에서는 고용의 질적인 측면, 혹은 심리적인 측면과 군 복무경험의 관계에 대 한 연구가 이루어져야 한다는 것을 제시하였는데, 이는 밀레니얼-Z세대의 특성을 고려하였을 때 앞으로 더 확대되어야 할 주제이다. 왜냐하면 밀레니얼-Z 세대는 워라벨을 중시하고, 집단보다 개 인주의 사고를 하며, 자아실현을 원하고, 공정성을 중요시하는 특성을 가지고 있으며, 이를 고려하 였을 때 단순히 임금을 많이 준다고 해서 좋은 직장으로 여기는 것이 아닌 질적이고 심리적인 측면 을 고려하기 때문이다. 즉, 밀레니얼-Z세대의 직업 경험에 대한 측정을 하기 위해서는 기존 세대와 
는 다르게 직무만족, 자아실현의 가능성 등 다양한 요소를 추가로 고려해야 정확한 측정이 될 수 있기 때문이다. 마지막으로, 이번 연구에서는 군 복무 경험자와 미경험자로 이분법적으로 표본을 구성하지 않았고, 징병제의 대상인 남성중 복무자와 면제자로만 집단을 구분하였는데 이는 성별 임 금격차로 인해 결과가 왜곡되는 것과 모병제를 통해 입대한 여성과의 인적자원의 차이가 결과에 미치는 영향력을 방지하기 위함이었다. 물론 면제자의 사유에 대해서 통제하지 않았기 때문에 완전 하다고 보기는 어려우나, 후속 연구에서도 군 복무경험과 임금의 차이를 정확히 측정하기 위해서는 성별 임금 격차의 가능성을 고려하여 군 복무자와 면제자를 비교하는 것이 유의미 할 것이다.

하지만, 이번 연구에도 여러 한계점을 가지고 있다. 첫째는 군 복무의 유형이 차이가 있음을 고 려하지 못했다는 것이다. 이는 최근 10년간 YP2007 데이터가 군 복무의 유형을 측정하지 않았기 때문에 해당 변수를 통제하지 못하였다. 하지만, 군에서 장교, 부사관 등 간부로 근무한 것과 사병 으로 근무한 것, 그리고 공익근무로 근무한 것에는 앞선 선행연구에서 밝혔듯이 인적자본개발의 차 이, 선별 기제로 작동하거나 국가, 회사 정책상 지원의 차이, 그리고 이번 연구에서 제시한 후광효 과 및 낙인효과의 차이가 분명히 존재할 수 있기 때문이다. 특히, 장교와 부사관으로 구성된 간부집 단의 경우에는 미군과 동일하게 모병을 통해서 군 복무를 경험한 인원들로, 해당 인원들에게는 후 광효과를 통한 선별 효과가 발생할 수 있기 때문이다. 후속 연구는 군 복무 경험자들을 장교, 부사 관, 사병, 공익근무로 분류하여 집단 간 차이를 분석한다면 군 복무경험과 고용시장이 가지는 상관 관계에 대한 폭넓은 이해를 제공할 수 있을 것이다. 또한, 이번 연구에서는 군 복무경험과 직무 만 족, 업무요구능력, 자존감에 대해서 측정하였으나, 일부 문항의 상관관계를 밝혔지만 이를 인과관 계라고 보기에는 어렵다. 후속 연구에서 새로운 척도를 개발하여 군 복무의 효과에 관해서 보다 직 접적으로 측정하거나, 혹은 매개효과와 조절효과를 지니는 변수들에 대해서 폭넓게 연구해야만 이 를 극복할 수 있을 것이다. 또한, 군 복무가 개인의 발전에 미치는 영향요소와 사회적 인식에 작용하여 고용주 혹은 인사담당자에 미치는 영향 등을 분리하여 연구한다면 역시 보다 폭넓은 이해를 가져올 수 있을 것이다. 마지막으로, 데이터의 특성상 인사담당자에 의한 선별기제에 대한 측정을 직접적으로 하지 못했다는 점에서도 한계를 보인다. 또한, 향후에는 인사담당자와 구성원을 쌍으로 측정하여 실제 로 군 복무경험이 선별기제로 작용하는지를 확인해 보는 연구가 필요할 것이며, 이 효과가 장교, 부사 관, 사병, 공익근무, 면제자의 복무유형별로 차이를 보이는지도 분석하는 것이 유의미할 것이다.

\section{Acknowledgements}

We would like to thank Editage (www.editage.co.kr) for English language editing.

\section{Declaration of Conflicting Interests}

The author(s) declared no potential conflicts of interest with respect to the research, authorship, and/or publication of this article. 
The effectiveness of military service experience on job experience / Donghwan Lee • Yunyoung Jung 109

\section{Reference}

Anastasi, A. (1988). Psychological testing (6th ed.) New York, USA: Macmillan Publishing Company. http://scholar.google.com/scholar_lookup?hl=en\&publication_year=1988\&author=A+Anastasi\& title=Psychological+testing

Angrist, J. (1995). Estimating the Labor Market Impact of Voluntary Military Service Using Social Security Data on Military Applicants. https://doi.org/10.3386/w5192

Angrist, J. D. (1998). Estimating the Labor Market Impact of Voluntary Military Service Using Social Security Data on Military Applicants. Econometrica, 66(2), 249. https://doi.org/10.2307/2998558

Bauer, T. K., \& Bender, S. (2004). Technological change, organizational change, and job turnover. Labour Economics, 11(3), 265-291. https://doi.org/10.1016/j.labeco.2003.09.004

Becker, G. S. (1980). Human capital (Vol. 3). Chicago: University of Chicago press.

Becker, Howard. (1963). Outsiders. New York: MacMillan.

Berger, M. C., \& Hirsch, B. T. (1983). The Civilian Earnings Experience of Vietnam - Era Veterans. The Journal of Human Resources, 18(4), 455. https://doi.org/10.2307/145439

Card, J. J. (1983). Lives after Vietnam: The personal impact of military service. Free Press.

De Tray, D. (1982). Veteran status as a screening device. The American Economic Review, 72(1), 133-142. https://www.jstor.org/stable/1808580

Eom, D. (2009). The Effect of Military Service on Wages in Korea. The Korean Journal of Applied Statistics, 22(4), 805-817. UCI: G704-000408.2009.22.4.008

Fredland, J. E., \& D LITTLE, R. (1985). Socioeconomic status of World War II veterans by race: An empirical test of the bridging hypothesis. Social Science Quarterly, 66(3), 533. http://search.proquest.com/openview/ec42d1e54a8841bfd9d21fd2f92ba662/1?pq-origsite=gs cholar\&cbl=1816420

Goffman, E. (1963). Stigma and social identity. Stigma: notes on the management of spoiled identity, Prentice Hall, Englewood Cliffs, NJ. https://books.google.com/books?hl=ko\&r=\&id=dxQhGJpBzUC\&oi=fnd\&pg $=$ PA116\&dq=Goffman, + E. $+(1963) .+$ Stigma + and + social + identity $. \& o t s=P X U z K w B X A 6 \& s i g=0 N$ Nj57chVhKfTVe1OjObPFOWO7A

Han, A. (2020). The Relationship between social stigma and self-esteem in out-of-school youth: The moderating effects of parent' and peer's attachment. The Journal of Learner-Centered Curriculum and Instruction, 20(1), 207-227. https://doi.org/10.22251/jlcci.2020.20.10.207 
Hisnanick, J. J. (2003). A great place to start: The role of military service on human capital formation. Labour, 17(1), 25-45. https://doi.org/10.22251/jlcci.2020.20.10.207

Jung, T., Yu, Y., \& Kwak, J. (2016). How Korean People See the Armed Forces and Military Services. Journal of Military History Studies, 141, 455-484. UCI : G704-SER000002076.2016..141.014

Kim, C., \& Seo, M. (2004). A Study on Prejudice and discrimination against the mentally ill. Korean Journal of Health Psychology, 9(3), 589-608. UCI : G704-000533.2004.9.3.004

Kim, D., \& Choi,. H. (2011). The Effects of Military Service Experience on Employment and Wage. Journal of The Korean Data Analysis Society, 13(3), 1599-1613. UCI : G704-000930.2011.13.3.037

Kim, H. (2001). A Study on the Effective PR Ideas for the Korean Military. Master's dissertation, Seoul: Chung-Ang University Graduate School of Mass Communication.

Kim, M., \& Lee, K., (2008). Format and scale effects on leniency error and halo effect in $360^{\circ}$ feedback. The Korean Journal of Industrial and Organizational Psychology, 21(2), 201 224. https://doi.org/10.24230/ksiop.21.2.200805.201

Kim, S. (2016). The Analysis of the Effect on Employment Period and the Income After a College Graduate. The Quarterly Journal of Defense Policy Studies, 32(4), 201-235. https://doi.org/10.22883/jdps.2017.32.4.007

Kim, Y., \& Kim, G. (2017). The Wage Effects of Military Service on Youth and Middle Aged Population. Korea Review of Applied Economics, 19(4), 131-167.

Lee, D., \& Kang, W. (2017). A Study on the feasibility of Transition from Conscription to Volunteer System in the Military: Focusing on Cost analysis. Innovation Studies, 12(1), 75 - 101. https://doi.org/10.46251/innos.2017.02.12.1.75

Link, B. G., \& Phelan, J. C. (2001). Conceptualizing stigma. Annual Review of Sociology, 27(1), 363-385. https://doi.org/10.1146/annurev.soc.27.1.363

Little, R. D., \& Fredland, J. E. (1979). Veteran status, earnings, and race: Some long term results. Armed Forces \& Society, 5(2), 244-260. https://doi.org/10.1177/0095327x7900500203

Major, B., Spencer, S., Schmader, T., Wolfe, C., \& Crocker, J. (1998). Coping with negative stereotypes about intellectual performance: The role of psychological disengagement. Personality and Social Psychology Bulletin, 24(1), 34-50. https://doi.org/10.1177/0146167298241003

Nam, T. (2016). The Role of CSR Activity's Halo Effect on Consumer Attitude Formation. Doctor dissertation, Seoul: Kyonggi University. Department of Business Administration Graduate School.

Newcomb, T. (1931). An experiment designed to test the validity of a rating technique. Journal 
The effectiveness of military service experience on job experience / Donghwan Lee Yunyoung Jung 111

of Educational Psychology, 22(4), 279-289. https://doi.org/10.1037/h0070737

Nisbett, R. E., \&Wilson, T. D. (1977). The halo effect: evidence for unconscious alteration of judgments. Journal of Personality and Social Psychology, 35(4), 250-256. https://doi.org/10.1037/0022-3514.35.4.250

Park, J. (2004). The Effect of Retailer Image on Private Brand Attitude: Halo Effect and Summary Construct. Journal of Channel and Retailing, 9(2), 101-122. UCI : G704-000527.2004.9.2.001

Richard, B., \& Wilhite, A. (1990). Military experience and training effects on civilian wages. Applied Economics, 22(1), 69-81. https://doi.org/10.1080/00036849000000052

Sampson, R. J., \& Laub, J. H. (1996). Socioeconomic achievement in the life course of disadvantaged men: Military service as a turning point, circa 1940-1965. American Sociological Review, 61(3), 347-367. https://doi.org/10.2307/2096353

Schwartz P. (1986) Jeremy Bentham's Democratic Despotism. In: Collison Black R.D. (eds) Ideas in Economics. British Association for the Advancement of Science. Palgrave Macmillan, London. https://doi.org/10.1007/978-1-349-18343-2_4

Shim, H. (2020). Effects of public stigma and self-stigma on the intention to seek professional help by Employees: Moderated mediating effect of others' approval accompanied with a sense of self-worth. Korea Journal of Counseling, 21(5), 255-277. https://doi.org/10.15703/kjc.21.5.202010.255

Steele, C. M., \& Aronson, J. (1995). Stereotype threat and the intellectual test performance of African Americans. Journal of Personality and Social Psychology, 69(5), 797-811. https://doi.org/10.1037/0022-3514.69.5.797

Teachman, J. (2004). Military service during the Vietnam era: Were there consequences for subsequent civilian earnings?. Social Forces, 83(2), 709-730. https://doi.org/10.1353/sof.2005.0021

Teachman, J. D., \& Call, V. R. (1996). The effect of military service on educational, occupational, and income attainment. Social Science Research, 25(1), 1-31. https://doi.org/10.1006/ssre.1996.0001

Teachman, J., \& Tedrow, L. (2007). Joining up: Did military service in the early all volunteer era affect subsequent civilian income?. Social Science Research, 36(4), 1447-1474. https://doi.org/10.1016/j.ssresearch.2007.03.002

Twenge, J. M., \& Crocker, J. (2002). Race and self-esteem: Meta-analyses comparing Whites, Blacks, Hispanics, Asians, and American Indians and comment on Gray-Little and Hafdahl (2000). Psychological Bulletin, 128(3), 371 - 408. https://doi.org/10.1037/0033-2909.128.3.371

Wells, F. L. (1907). A statistical study of literary merit: With remarks on some new phases of the method(Vol. 13). Science Press.

$$
\begin{aligned}
& \text { 원 고 접 수 일 2020년 11월 22일 } \\
& \text { 원 고 수 정 일 2020년 12월 15일 } \\
& \text { 게 재 확 정 일 2020년 12월 24일 }
\end{aligned}
$$




\title{
국문초록
}

https://doi.org/10.37944/jams.v3i3.84

\section{군 복무경험이 직업 경험에 미치는 영향 분석}

\author{
이동환* 정윤영**
}

본 연구는 군 복무경험이 향후 직업 경험에 미치는 영향을 밝히는데 그 목적을 두고 있다. 이번 연구에서는 최근 군 복무 단축, 인구절벽 등으로 군 복무 제도의 변화가 요구되고, 모병제 도입과 여성 징병제 등 여러 사회적 담론이 이루어지고 있으나, 군 복무경험이 향후 양적 - 질적 직업 경험에 미치는 영향에 관한 연구가 부족하며, 연구 결과들이 다소 상이함을 밝히고 이를 해결하기 위해 진행되었다. 본 연구에서는 군 복무 경험 자의 임금이 높은 원인이 군 복무경험 여부에 따른 선별 효과에 의해 발생한 것이라 귀인하고, 후광효과와 낙 인효과를 통해 이를 설명하고자 하였으며, 한국과 미국의 차이에 의한 선별 효과의 차이에 집중하였다. 이번 연구는 YP2007 12차 데이터를 활용하여 군 복무 경험자와 면제자의 두 집단에 대해서 비교 연구를 진행하였 으며, 군 복무경험이 고용에 미치는 영향을 양적 요소 뿐 아닌 질적 요소와 함께 고려하기 위해 직업 경험을 측정하고자 하였다. 이때 직업 경험을 측정한 양적 변수는 임금이며 질적 변수는 정규직 여부, 직장 만족, 업 무 요구수준이다. 해당 변수들의 군 복무 경험자 집단과 면제집단 간 차이를 분석하기 위해 카이제곱 검정과 독립표본 t-test를 진행하였다. 분석결과 임금과 정규직 비율은 군 복무 경험자 집단에서 유의미하게 높게 나 타났으며, 직장 만족과 업무요구능력은 측정한 일부 문항들에서 유의미하게 군 복무 경험자에게 높게 나타나 며 군 복무경험이 향후 직업 경험에 정적인 영향을 미친다는 것을 밝혀냈다.

주제어 : 군 복무 경험, 직업 경험, 선별효과, 후광효과, 낙인효과

* (제1저자) 육군사관학교, 경영학과, 강사, hwan8739@gmail.com, orcid 0000-0002-5217-6804

** (교신저자) 육군사관학교, 경영학과, 조교수, 4348901@gmail.com, orcid 0000-0001-7667-0746 